Jurnal ELTIKOM, Vol. 1 No.2, Desember 2017, Hal 102-112 ISSN 2598-3245 (Print), ISSN 2598-3288 (Online)

Tersedia Online di http://eltikom.poliban.ac.id

\title{
PENGGUNAAN KOMUNIKASI BLUETOOTH PADA SMARTPHONE ANDROID UNTUK PENGIRIMAN DATA PADA JAM DIGITAL BERBASIS ARDUINO
}

\author{
Sarifudin'), Manshur ${ }^{2)}$, Angga Tirtana ${ }^{3)}$ \\ ${ }^{1,2,3)}$ Politeknik Negeri Banjarmasin \\ e-mail: sarif@poliban.ac.id ${ }^{1)}$, manshuri.yusuf@gmail.com ${ }^{2}$, angga.tirtana@yahoo.com ${ }^{3)}$
}

\begin{abstract}
The schedule of prayer is very important akan ada.Masa Today many in the mosque as well as in homes that usually have a calendar and the viewer time of eternal prayer, but it looks so small that it can not be seen from a great distance. This prayer timepiece uses a display display dot matrix P4, displaying the date, digital clock as well as the 5th time of the prayer. So that prayer times can be changed in real time according to time and day changes, and can be seen from a great distance and can be used to maximize the time available. This research produces a digital clock time system that uses dot-matrix as display, RTC as real time clock, bluetooth as sender of data from smart mobile device android, and buzzer as alarm. So that the system formed the digital clock time of this prayer. Based on design, implementation and testing, the arduino-based digital time-shaped design tool can be used for digital clocks and bookmarks and prayer time reminders.
\end{abstract}

Keywords: dot matrix, digital clock, arduino, smart phone android

\section{ABSTRAK}

Penunjuk jadwal shalat itu sangat penting akan adanya.Masa Sekarang ini banyak di masjid maupun di rumah-rumah yang biasanya sudah terdapat kalender maupun penampil waktu sholat abadi, akan tetapi tampilannya sangat kecil sekali sehingga tidak dapat dilihat dari jarak yang sangat jauh. Penunjuk waktu shalat ini mengunakan display display dot matrix P4, menampilkan tanggal, jam digital serta ke-5 waktu shalat tersebut. Sehingga penunjuk waktu sholat yang dapat secara real time berubah mengikuti perubahan waktu dan hari, serta dapat dilihat dari jarak yang cukup jauh dan dapat digunakan untuk lebih memaksimalkan waktu yang ada. Penelitian ini menghasilkan sistem jam digital waktu sha-lat yang mengunakan dotmatrix sebagai display, RTC sebagai real time clock, bluetooth sebagai pengirim data dari perangkat smart handphone android, dan buzzer sebagai alarm. Sehingga terbentuk sistem jam digital waktu shalat ini. Berdasarkan perancangan, implementasi dan pengujian, maka alat rancang bangun jam digital waktu shalat berbasis arduino ini dapat digunakan untuk jam digital dan penunjuk serta pengingat waktu shalat.

Kata Kunci: dot matrix, jam digital, arduino, smart handphone android

\section{PENDAHULUAN}

$\mathbf{S}$ eiring dengan berkembangnya teknologi yang sangat cepat, pada zaman sekarang ini dikembangkan teknologi dengan tujuan untuk mempermudah kegiatan manusia dalam kehidupan sehari-hari. Perkembangan teknologi mikrokontroller misalnya telah membawa era baru dalam dunia eletronika. Salah satu bentuk penerapannya adalah pengendali huruf berjalan Running Text, alat ini berfungsi untuk men-ampilkan informasi berupa tulisan berjalan menggunakan lampu LED sebagai display. Dalam perancangan alat ini menggunakan mikrokontroller ATmega328 sebagai pengolah data sekaligus menyimpan data-data biner yang diperlukan untuk mengendalikan dot matrix LED sebagai output data. Pada perancangan juga di kembangkan sebuah aplikasi android yang digunakan sebagai pengirim data melalui aplikasi Jadwal Sholat Kontrol yang akan di terima oleh bluetooth HC-06 dan di baca oleh mikrokontroller kemudian di tampilkan pada display dot matrix.

Rancangan ini sangat bermanfaat dalam dunia advertising (reklame), karena dapat menampilkan tulisan berupa huruf atau angka berjalan ada displai yang terdiri dari susunan LED secara dot matrix. Pengubahan waktu dan pengumuman selain menggunakan PC juga dapat mengubahnya melalui aplikasi Jadwal Sholat Kontrol yang di instal pada handphone android. 


\section{TINJAUAN PUSTAKA}

\section{A. Arduino Uno}

Proyek arduino berawal dilvre, italia pada tahun 2005. Pendirinya adalah Massimo Banzidan David Cuartiellez. Aeduino adalah pengendali mikro single-board yang bersifat open-source, diturunkan dari Wiring platform, dirancang untuk memudahkan penggunaan elektronik dalam berbagai bidang. Hardwarenya memiliki prosesor Atmel AVR dan softwarenya memiliki bahasa pemrograman sendiri.

Arduino Uno adalah papan mikrokontroler berdasarkan ATmega328 (datasheet). Ini memiliki 14 digital pin input / output (dimana 6 dapat digunakan sebagai output PWM), 6 input analog, resonator keramik $16 \mathrm{MHz}$, koneksi USB, jack listrik, header ICSP, dan tombol reset. Ini berisi semua yang diperlukan untuk mendukung mikrokontroler; hanya menghubungkannya ke komputer dengan kabel USB atau power itu dengan adaptor AC-DC atau baterai untuk memulai menggunakannya.

Uno berbeda dari semua papan sebelumnya di bahwa itu tidak menggunakan chip driver FTDI USBto-serial. Sebaliknya, fitur Atmega16U2 (Atmega8U2 sampai versi R2) diprogram sebagai konverter USB-to-serial. Revisi ke 2 Uno memiliki resistor menarik garis 8U2 HWB line to ground, sehingga lebih mudah untuk dimasukkan ke dalam mode DFU. Revisi ke 3 memiliki fitur-fitur baru berikut: 1,0 pinout: menambahkan SDA dan pin SCL yang dekat dengan pin AREF dan dua pin baru lainnya ditempatkan dekat dengan pin RESET, yang IOREF yang memungkinkan perisai untuk beradaptasi dengan tegangan yang tersedia dari papan. Di masa depan, perisai akan kompatibel dengan kedua papan yang menggunakan AVR yang beroperasi dengan 5V dan dengan Arduino Due yang beroperasi dengan 3.3V. Yang kedua adalah pin tidak terhubung, yang disediakan untuk tujuan masa depan.

-Stronger RESET sirkuit.

-Atmega 16U2 menggantikan 8U2.

"Uno" berarti satu di Italia dan diberi nama untuk menandai peluncuran Arduino 1.0. The Uno dan versi 1.0 akan menjadi versi referensi Arduino, bergerak maju. The Uno adalah yang terbaru dalam serangkaian USB Arduino papan, dan model referensi untuk platform Arduino; untuk perbandingan dengan versi sebelumnya, lihat indeks Arduino papan.

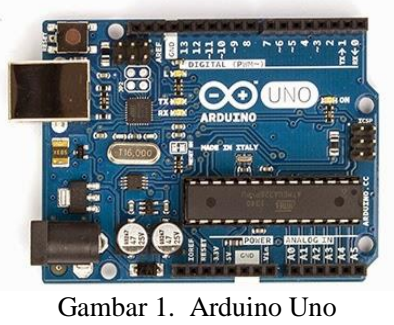

\section{B. Bluetooth HC-06}

Bluetooth menghubungkan dan dapat dipakai untuk melakukan tukar-menukar informasi di antara peralatan-peralatan. Bluetooth beroperasi dalam pita frekuensi 2,4 Ghz dengan menggunakan sebuah frequencyhopping traceiver yang mampu menyediakan layanan komunikasi data dan suara secara real time antara host-host bluetooth dengan jarak terbatas.

Modul Bluetooth HC-06/BO adalah modul siap pakai untuk membuat embedded project memiliki kemampuan berkomunikasi secara serial dengan protokol standar Bluetooth versi 2.3.5 Papan Inti HC06 (menggunakan chipset CSR BC417) sudah dipasangkan dengan adaptor koneksi (backplane breakout board) sehingga mudah untuk digunakan, cukup menghubungkan modul ini dengan kabel koneksi serial ke pin RX/TX darimikrokontroler. Modul ini dioperasikan lewat perintah AT (AT commands) yang dikirimkan secara serial.

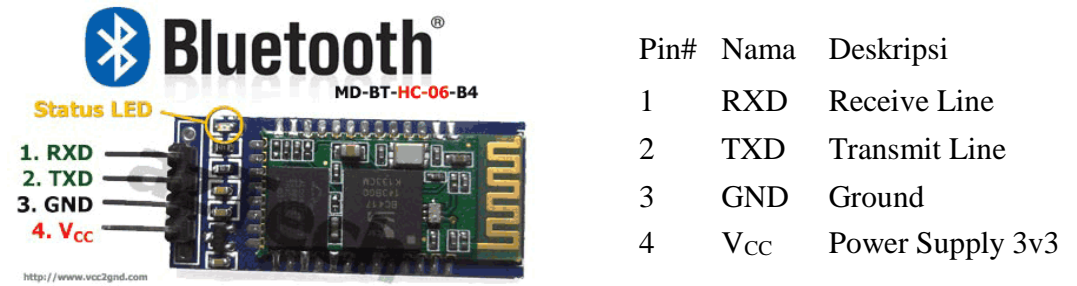

Gambar 2. Bluetooth HC-06 


\section{Buzzer}

Buzzer merupakan sebuah komponen elektronika yang masuk dalam keluarga transduser, yang dimana dapat mengubah sinyal listrik menjadi getaran suara. Nama lain dari komponen ini disebut dengan beeper. Dalam kehidupan sehari - hari, umumnya digunakan untuk rangkaian alarm pada jam, bel rumah, perangkat peringatan bahaya, dan lain sebagainya. Jenis buzzer yang sering ditemukan dipasaran yaitu tipe piezoelectric. Dikarenakan tipe ini memiliki kelebihan seperti harganya yang relatif murah, mudah diaplikasikan ke dalam rangkaian elektronika.

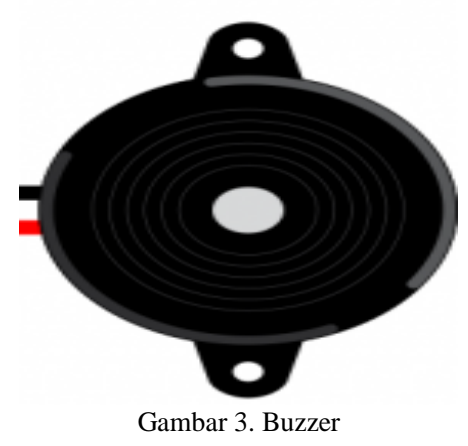

\section{Catu Daya}

Catu daya digunakan untuk mensuplai tegangan dan arus kesemua rangkaian agar dapat berfungsi atau bekerja,Sumber catu daya yang besar adalah sumber bolak-balik AC (alternating current) dari pembangkit tenaga listrik. Untuk itu diperlukan suatu perangkat catu daya yang dapat mengubah arus AC menjadi DC.

Prinsip penyearah (rectifier) yang paling sederhana ditunjukkan pada gambar berikut ini. Transformator diperlukan untuk menurunkan tegangan AC dari jala-jala listrik pada kumparan primernya menjadi tegangan AC yang lebih kecil pada kumparan sekundernya.

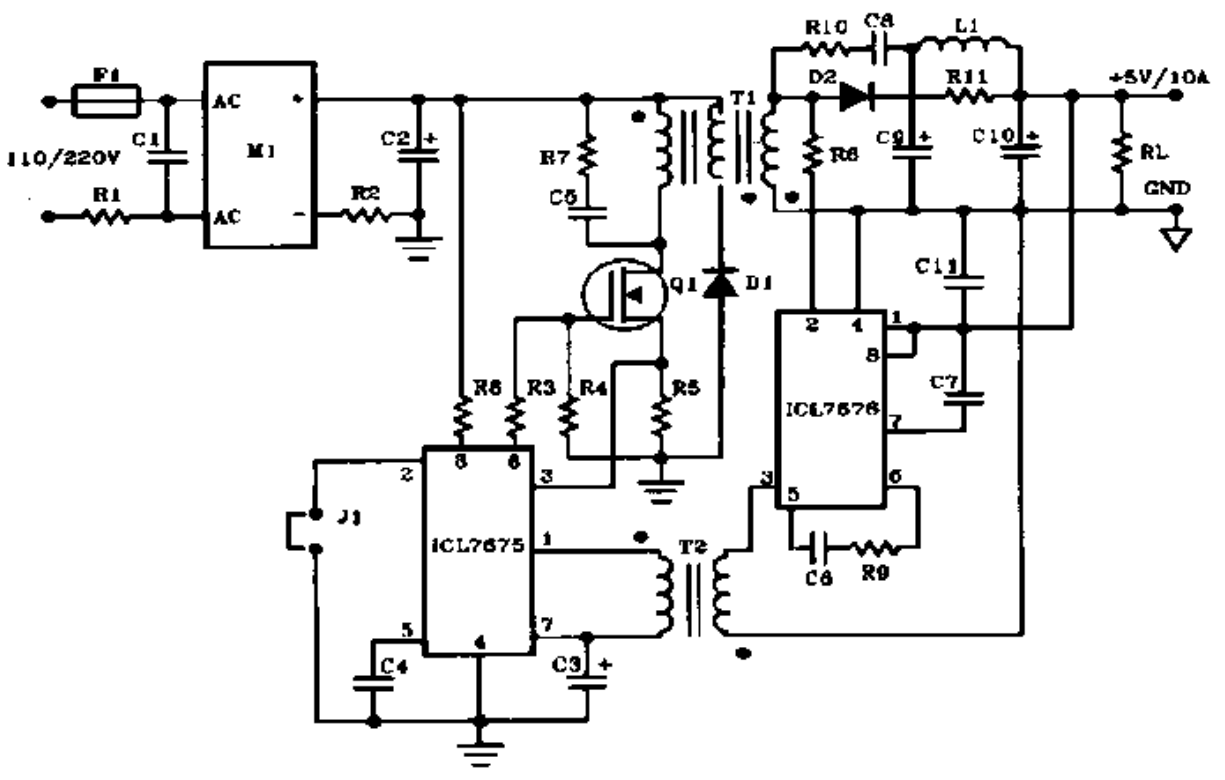

Gambar 4. Rangkaian Catu Daya

\section{E. Display Dot Matrix P4}

Display dot matrik berfungsi menampilkan data yang di terima olehArduino. Pada rangkaian terdapat beberapa komponen penyusun seperti shift register IC SN74HC595 dan led dot matrix. Dot matrix adalah susunan dari beberapa LED (Light Emiting Dioda). Jumlah LED penyusun dot matrix tergantung dari kebutuhan untuk menampilkan karakter tulisan. Dot matrix disini berfungsi sebagai penampil yang dapat menampilkan semua karakter yang berupa huruf dan angka. Selain itu dot matrixjuga lebih fungsional dan relatif fleksibel (dalam hal ukuran) di banding dengan penampilyang biasa dipakai seperti seven segmen maupun LCD. 


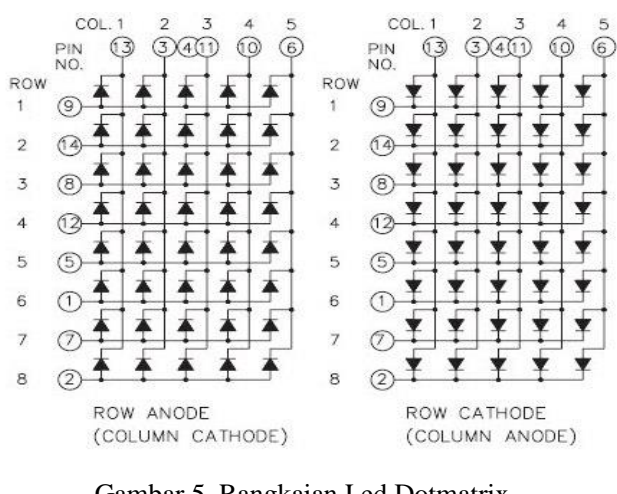

\section{F. $\quad$ Shift Register IC SN74HC595}

IC SN74HC595 merupakan IC register geser yang melakukan proses pergeseran data. Penggeseran data diperlukan baik dalam pengiriman data secara berderet (serial) maupundalam perhitungan aljabar perkalian dan pembagian. Data dikirim melalui saluran komunikasi bit demi bit. Data yang disimpan atau diolah dalam computer selalu bersifat parallel. Agar dapat dikirim melalui satu saluran komunikasi. Maka data beberapa bit itu harus bergeser keluar satu demi satu. Begitu juga disisi penerima,bit demi bit data yang diterima dari saluran komunikasi harus digeser sampai membentuk satu satuan data paralel agar dapat disimpan/diolah dalam register komputer. Jadi dalam komunikasi data, register geser memegang berperanan sangat penting.Dalam perhitungan aritmatika (aljabar), computer selalu melaksanakan operasi perkalian dan pembagian dengan melakukan penambahan atau pengurangandisertai penggeseran kekiri/kekanan secara berulang-ulang. Perlu dicatat bahwa suatu data bilangan yang digeser ke kiri maka harga bilangan itu akan digandakan menjadi dua kali harga semula dan bila satu bilangan biner digeser kekanan,maka harga menjadi setengah dari harga sebelum digeser. Sebgai contoh, kalu biner 0110, yang setera dalam decimal adalah 6, digeser kekanan satu kedudukan aka harga menjadi $0011\left(3_{10}\right)$ sedangkan digeser kekiri harganya menjadi $1100\left(12_{10}\right)$ perhatikan bahwa pergeseran yang normal dilakukan dengan menabahkan bit 0 pada posisi paling kanan pada pergeseran ke kiri dan pada kedudukan paling kiri pada penggeseran kekanan. Kerena cacah bit yang dapat ditapung oleh satu register sudah tertentu, maka bit diujung lain akan hilang, yaitu bit yang paling kanan pada penggeseran ke kanan dan bit paling kiri pada penggeseran ke kiri.Register atau disebut dengan memori adalah suatu rangkaian logika yang mampu menyipan data dalam bentuk bilangan biner. Fungsi dari register, selain sebagai penyimpanan data juga untuk menghindari berkedipnya angka yang ditunjungkan oleh display pada saat menerima pulsa-pulsa yang diberikan oleh dekoder.
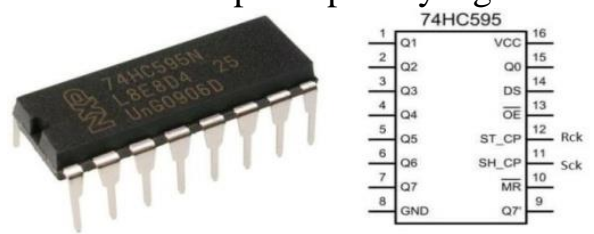

Gambar 6. Shift Register

Register dapat memindahkan bit-bit yang tersimpan ke kiri. Register geser dikelompokkan sebagai urutan rangkaian logika, sehingga register geser juga dapat digunakan untuk mengubah data seri ke paralel data paralel ke seri. Register geser (shift register) merupakan salah satu piranti fungsional yang banyak digunakan dalam sistem digital. Tampilan pada layar kalkulator dimana angka bergeser ke kiri setiap kali ada angka baru yang diinputkan menggambarkan karekteristik register geser tersebut. Register geser ini terbangun dari flip-flop. Register geser dapat digunakan sebagai memori sementara, dan data yang tersimpan didalamnya dapat digeser ke kiri dan ke kanan. Register geser juga dapat digunakana untuk mengubah data seri ke paralel atau data paralel ke seri.

\section{G. $\quad$ RTC DS3231}

Real Time Clock merupakan suatu chip (IC) yang memiliki fungsi sebagai penyimpan waktu dan tanggal. RTC DS3231 merupakan Real-time clock (RTC) yang dapat meyimpan data-data detik, menit, jam, tanggal, bulan, hari dalam seminggu, dan tahun valid hingga 2100. RTC DS3231 adalah IC yg 
mempunyai clock sumber sendiri dan internal batery untuk menyimpan data waktu dan tanggal. Sehingga jika system komputer / microcontroller mati waktu dan tanggal didalam memori RTC tetap uptodate. 56-byte, battery-backed, RAM nonvolatile (NV) RAM untuk penyimpanan

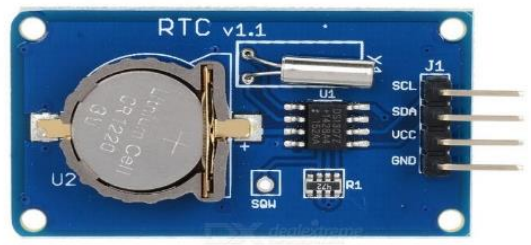

Gambar 7. RTC DS3231

RTC DS3231 merupakan Real-time clock (RTC) dengan jalur data parallel yang memilikiAntarmuka serial Two-wire (I2C), Sinyal luaran gelombang-kotak terprogram Programmable squarewave, Deteksi otomatis kegagalan-daya (power-fail) dan rangkaian switch, Konsumsi daya kurang dari 500nA menggunakan mode baterai cadangan dengan operasional osilator.Tersedia fitur industri dengan ketahanan suhu: $-40^{\circ} \mathrm{C}$ hingga $+85^{\circ} \mathrm{C}$. Tersedia dalam kemasa 8-pin DIP atau SOIC.

\section{H. Android}

Android adalah sistem operasi berbasis Linux yang dipergunakan sebagai pengelola sumber daya perangkat keras, baik untuk ponsel, smartphone dan juga PC tablet. Secara umum Android adalah platform yang terbuka (Open Source) bagi para pengembang untuk menciptakan aplikasi mereka sendiri untuk digunakan oleh berbagai piranti bergerak.

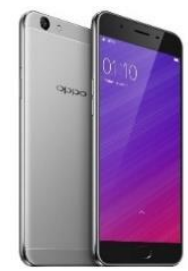

Gambar 8.Smarthphone Android

Pengembangan perangkat lunak Android adalah proses di mana aplikasi baru diciptakan untuk sistem operasi Android. Aplikasi tersebut biasanya dikembangkan dalam bahasa pemrogramanJava dengan menggunakan Software Development Kit (SDK) Android.Sebuah riset menunjukkan bahwa lebih 67\% pengembang aplikasi seluler menggunakan platform Android.

\section{App Inventor}

App Inventor adalah aplikasi web sumber terbuka yang awalnya dikembangkan oleh Google, dan saat ini dikelola oleh Massachusetts Institute of Technology (MIT). App Inventor memungkinkan pengguna baru untuk memprogram komputer untuk menciptakan aplikasi perangkat lunak bagi sistem operasi Android. App Inventor menggunakan antarmuka grafis, serupa dengan antar muka pengguna pada Scratch dan StarLogo TNG, yang memungkinkan pengguna untuk men-drag-anddrop objek visual untuk menciptakan aplikasi yang bisa dijalankan pada perangkat Android. Dalam menciptakan App Inventor, Google telah melakukan riset yang berhubungan dengan komputasi edukasional dan menyelesaikan lingkungan pengembangan online Google.

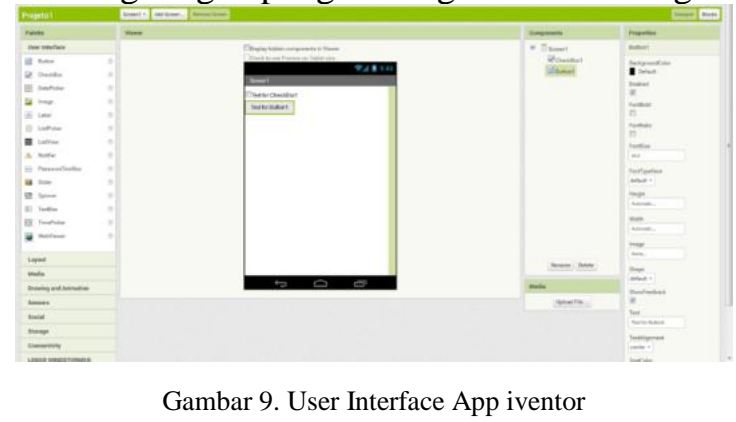




\section{PERANCANGAN SISTEM}

\section{A. Blok Diagram Display Dot Matrix}

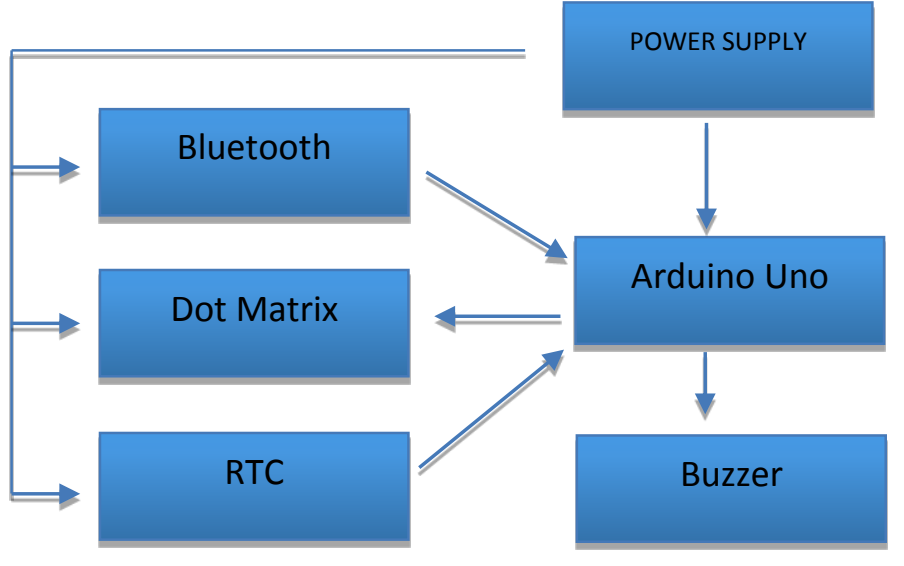

Gambar 10. Blok Diagram

Fungsi Arduino uno yaitu sebagai pengontrol dot matrix. Bluetooth dan RTC juga merupakan inputan data yang akan di proses Arduino. Adapun fungsi shift register yaitu menggeser bit yang dapat menampilkan sebuah karakterpada dot matrix,pergeseran bit itu di kontrol oleh Arduino. Real Time Clock (RTC) merupakan suatu chip (IC) yang memiliki fungsi sebagai penyimpan waktu dan tanggal. Dot matrix sebagai penampil yang akan menampilkan karakter sesuai data arduino melalui shift register.

\section{B. Perancangan Dan Cara Kerja Sistem}

Perancangan dilakukan meliputi diagram blok dan pembahasan masing-masing blok serta cara kerja system secara keseluruhan. Arduino merupakan komponen pemproses utama yang mengatur kerja seluruh komponen yang terdapat di dalam sistem. power supplai atau catu daya mempunyai keluaran tegangan sebesar 5 Volt digunakan untuk mensuplai mikrokontroller, bluetooth, RTC dan dot matrik. Data huruf atau angka yang tersimpan di mikro akan di tampilkan oleh dot matrik satu per satu perkolom secara multiplexing oleh shift register.Hal ini akan dilakukan secara berurutan pada dot matik berikutnya sampai dot matik terakhir yang terpasang.

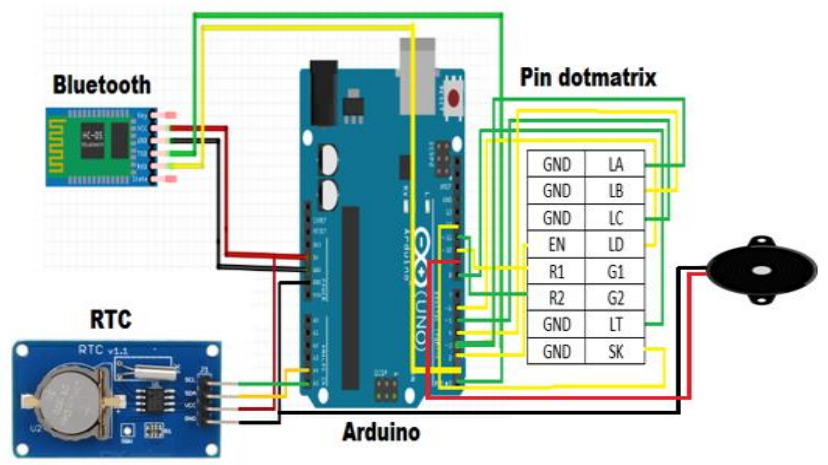

Gambar 11. Perancangan dan cara kerja sistem

\section{Flowchart Tampilan Jam Digital}

Di bawah ini merupakan flowchart jam digital waktu sholat dari tampilnya sebuah karakter, masuknya jadwal sholat, tampilnya running text, hingga update data dari applikasi pengontrolan : 


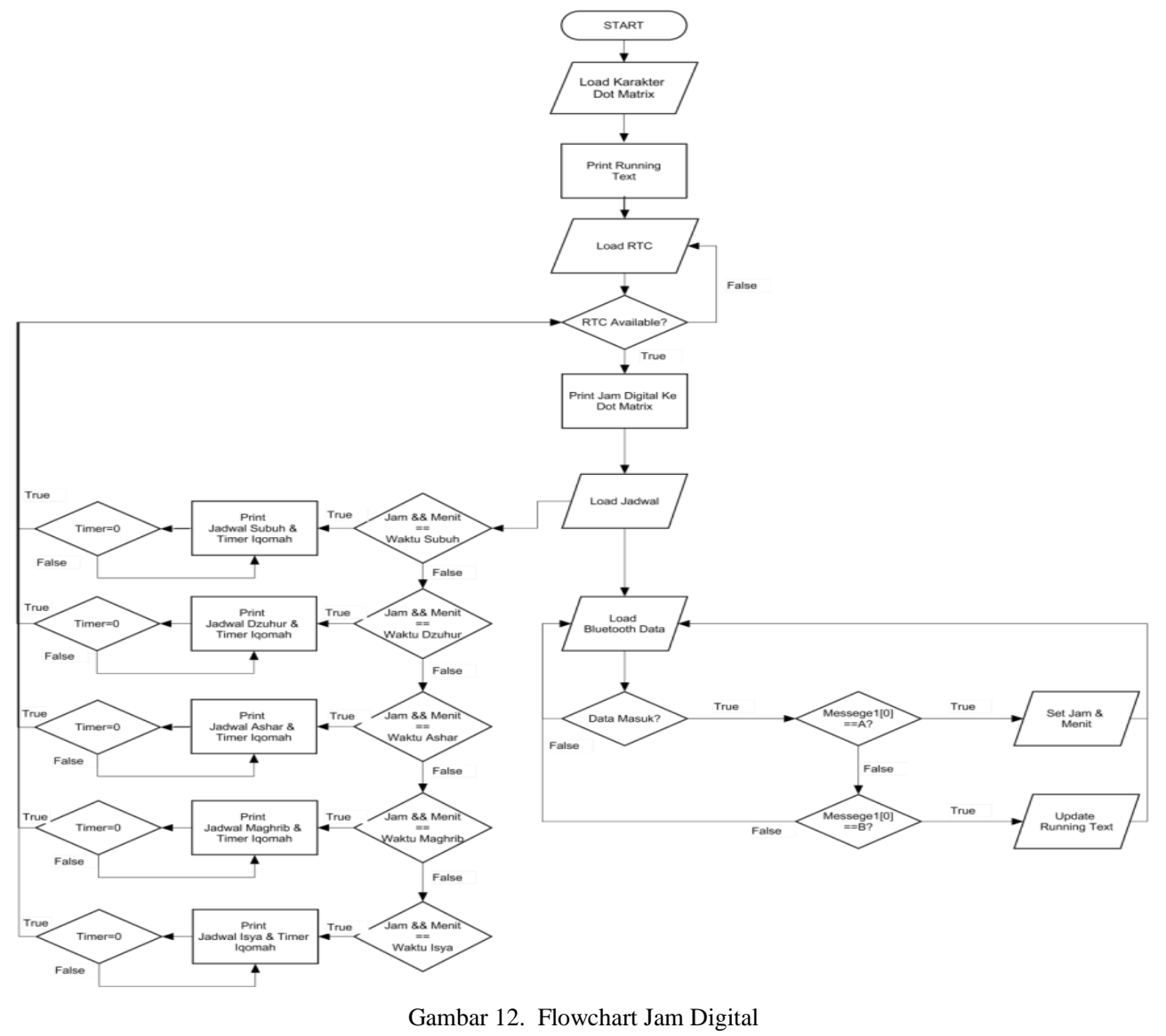

Dari flowchart di bawah ialah untuk menyetting data input dan data output pada aplikasi android jadwal sholat kontrol. Setelah itu data tersebut dikirimkan yang akan di terima oleh bluetooth untuk di proses oleh arduino dan akan di tampikan karakter pada dot matrik.

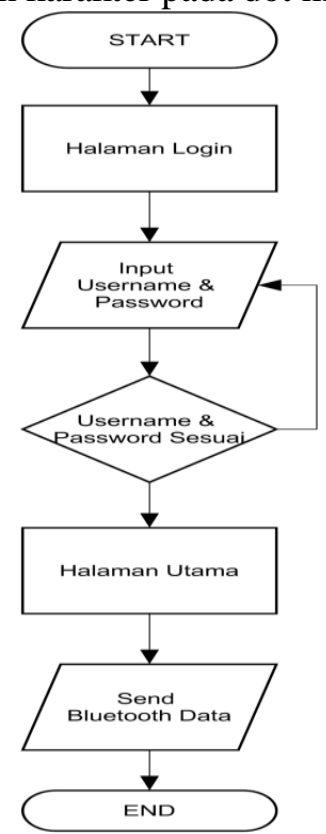

Gambar 13. Flowchart aplikasi pengontrol jam digital

\section{Rangkaian RTC DS3231}

DS3231 adalah sebuah IC yang dapat digunakan sebagai pengaturan waktu yang meliputi detik, menit, jam, hari, tanggal, bulan dan tahun. Pengaksesan data dilakukan dengan sistem serial sehingga 
hanya membutuhkan dua jalur untuk komunikasi yaitu jalur clock untuk membawa informasi data clock dan jalur data yang membawa data. RTC DS3231 memiliki register yang dapat menunjukkan waktu dalam detik, menit, jam, tanggal, bulan dan tahun. RTC ini didesain dengan 128 lokasi RAM yang terdiri dari 15 byte untuk data waktu serta kontrol, dan 113 byte sebagai RAM yang dapat digunakan sebagai RAM pada umumnya. RTC DS 1307 menggunakan bus yang termultipleks sehingga bisa menghemat penggunaan pin pada mikrokontroler. Berikut adalah gambar rangkaian RTC DS3231 :

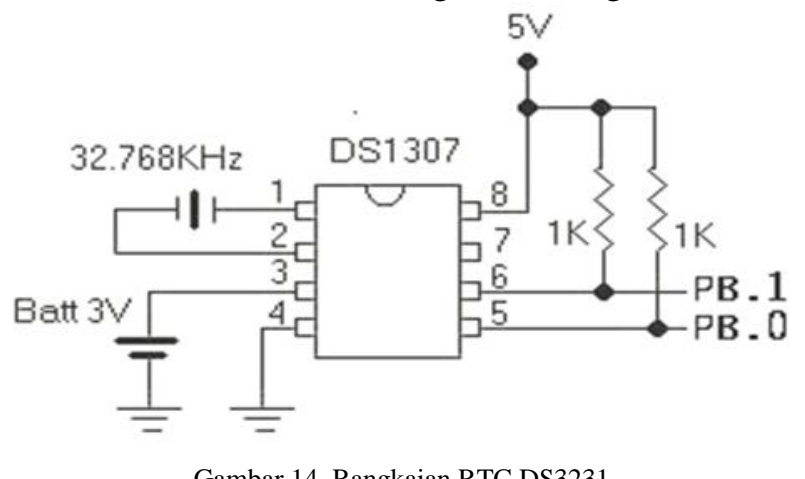

Gambar 14. Rangkaian RTC DS3231

\section{HASIL DAN PEMBAHASAN}

\section{A. Pengujian Dot Matrix}

1. Tampilan dot matrix ketika tiba waktu sholat. Nama waktu sholat akan muncul secara berkedip terus menerus selama 1 menit.

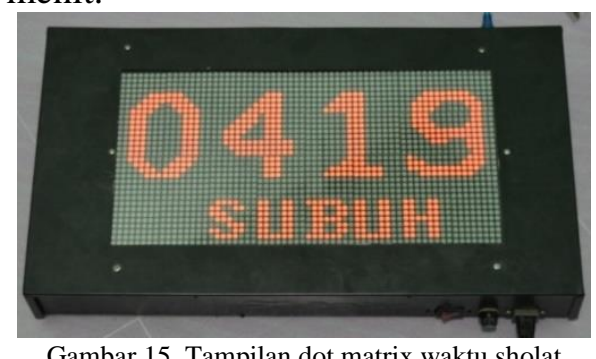

2. Tampilan dot matrix ketika telah melewati satu menit dari jadwal sholat. Hitung mundur akan dimulai dan running text pada baris kedua menampilkan tulisan "IQOMAH" secara berkedip.

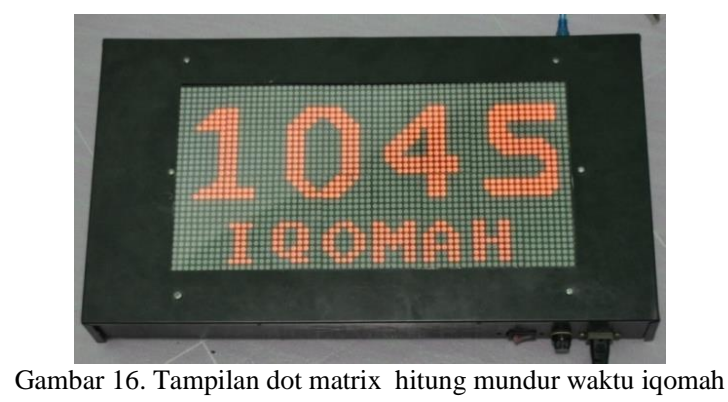

3. Tampilan dot matrix ketika tidak pada waktu jam-jam sholat. Baris pertama menampilkan jam digital, sedangkan pada baris bawah menampilkan beberapa informasi seperti waktu sholat, hadist, dan agenda yang akan dilakukan pada hari itu.

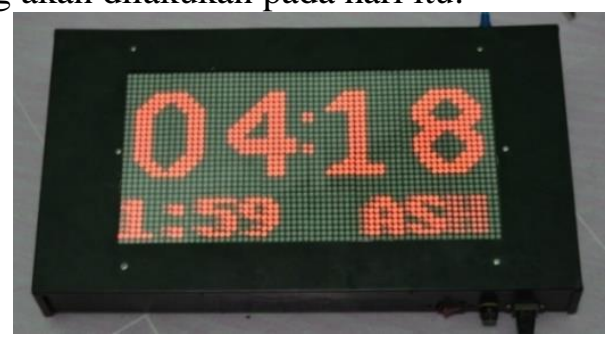

Gambar 17. Tampilan dot matrix menampilkan jam dan jadwal sholat 


\section{B. Pengujian Aplikasi Android}

Dalam pengujian aplikasi ini hadware bluetooth harus sudah terhubung dengan android. Aplikasi ini digunakan untuk mengirim data yang akan di terima oleh bluetooth yang sudah terhubung oleh android untuk ditampilkan ke display dot matrix. Berikut adalah cara pengoperasian aplikasi dan penambahan perangkat Bluetooth.

Langkah-langkah Menambahkan Perangkat Bluetooth HC-06 pada handphone Android :

1. Pilih Menu Pengaturan dan menu Bluethooth

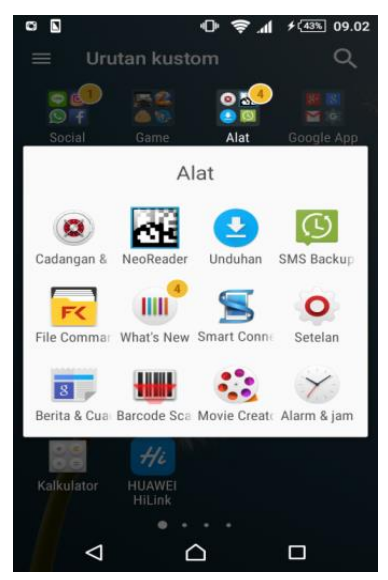

Gambar 18.Menu Handphone

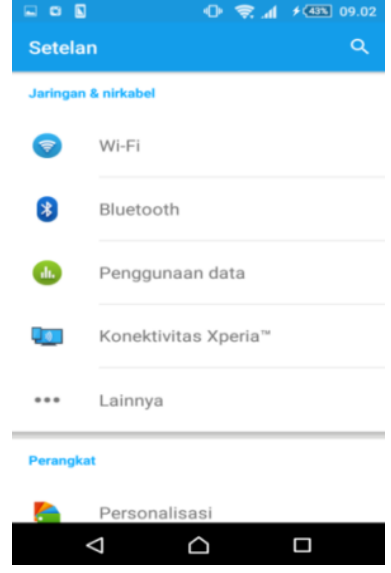

Gambar 19. Isi menu setting

2. Aktifkan bluetooth dan Pilih perangkat yang ingin di koneksikan

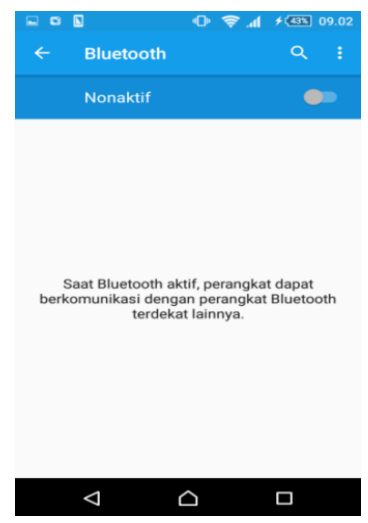

Gambar 20. Menu Setting Bluetooth
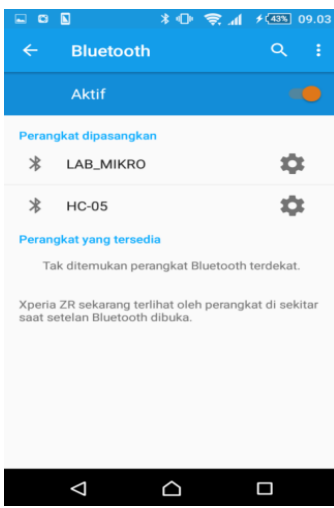

Gambar 21.Isi menu bluetooth ketika aktif

3. Masukkan password, biasanya " 0000 " atau " 1234 "

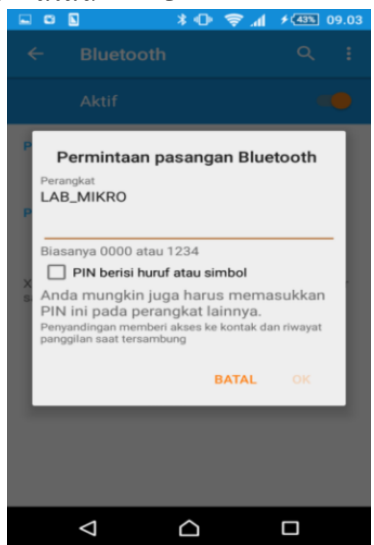

Gambar 22. Konformasi sandi bluetooth 
Langkah-langkah penggunaan aplikasi pengontrol jam digital

1. Buka aplikasi jam digital

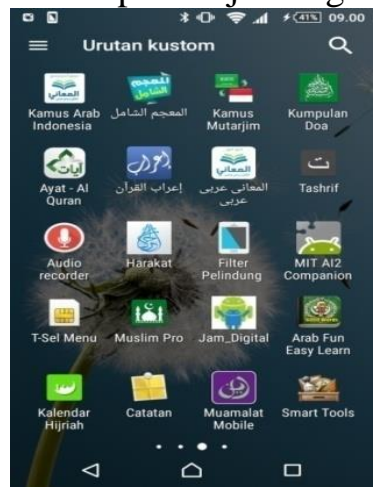

Gambar 23.Menu Handphone

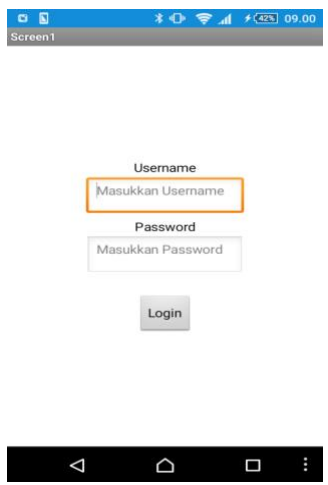

Gambar 24. Tampilan Login

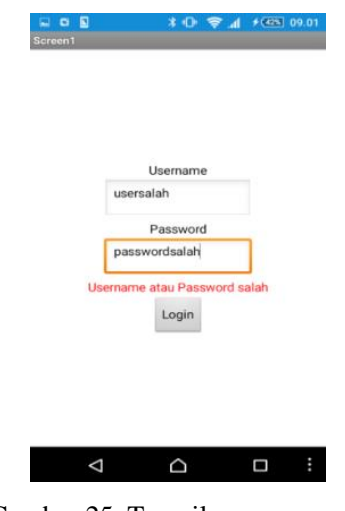

Gambar 25. Tampilan username

2. Masukkan username dan password

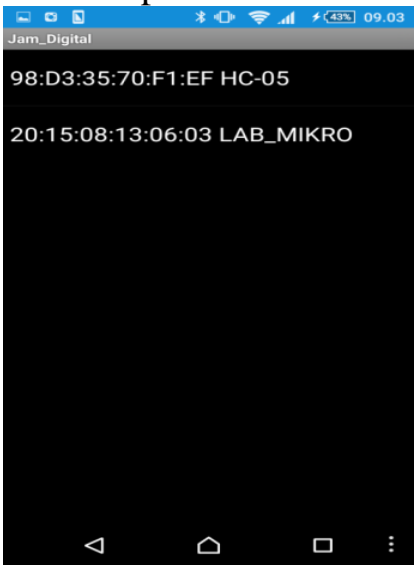

Gambar 26. Tampilan Aplikasi

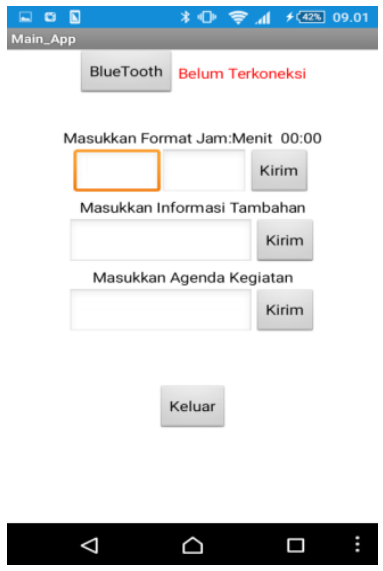

Gambar 27. Tampilan list perangkat bluetooth

3. Masukkan input pada aplikasi untuk pengontrolan jam digital
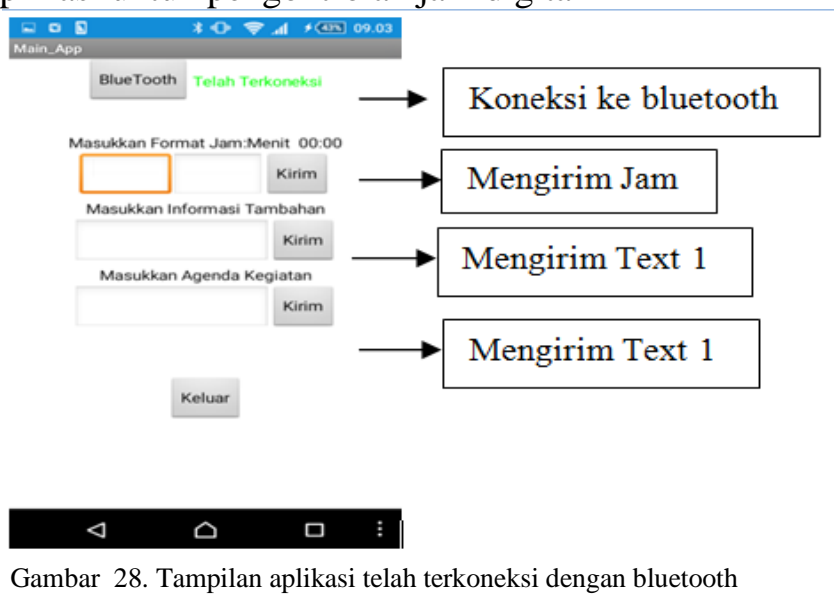

\section{KESIMPULAN}

1. Kemampuan arduino uno sudah sangat baik dalam menjalankan program dotmatrik dan untuk menerima komunikasi data input yg diberikan via bluetooth, serta kemudahan dalam pembuatan programnya.

2. Aplikasi App Inventor bekerja dengan baik, sehingga program smartphone yang kita buat dapat dimanfaat secara maksimal dan mudah di jalankan.

3. Catu daya yang di perlukan untuk menyalakan display dotmatrik untuk lebih stabil adalah arus 3 ampere dengan tegangan 5 volt . 
4. RTC DS3231 merupakan Real-time clock yang dapat meyimpan data-data detik, menit, jam, tanggal, bulan, hari dalam seminggu, dan tahun.

5. Aplikasi Jadwal Sholat dapat berkerja sesuai harapan, sehingga projek ini dapat di selesai dengan mudah.

Saran :

1. Diharapkan pengembangan pembuatan displai dotmatrik agar dapat di kontrol dengan jarak lebih jauh dibandingkan dengan bluetooth.

2. Tingkatkan animasi tulisan pada tampilan displai dot matrix agar lebih menarik.

3. Diharapan adanya pengembangan aplikasi terbaru dari android yang dapat lebih memudahkan dan peningkatan kemampuan pengendalian kontrolnya.

\section{DAFTAR PUSTAKA}

[1] Kadir , Abdul. ,"Panduan Praktis Mempelajari Aplikasi Mikrokontroler Dan Pemogramannya Menggunakan Arduino,”.,Andi, Yogyakarta, 2012.

[2] Mulyadi.." Android App Inventor: Membuat Aplikasi Android tanpa Kode Program. "Yogyakarta: Multimedia Center. 2011

[3] Arkanuddin, Mutoha., "Menentukan Waktu Shalat", http://www.rukyatulhilal.org/waktu shalat/, 2009.

[4] Perkasa, Brian Jaya,.". Tutorial Dasar Komunikasi Bluetooth dengan Arduino untuk ON/OFF LED. “ http://www.bjp.web.id/2016/04/tutorial-dasar-komunikasi-bluetooth.html. Diakses pada 21 Juli 2017.

[5] KEMENAG, Badan Hisab dan Rukyat.Jadwal Sholat Abadi untuk Banjarmasin. http://icukuk.blogspot.com/2014/03/jadwal-shalatsepanjang-masa.html.Diakses pada 21 Juli 2017

[6] Ary Zona, Ratna Aisuwarya, M.Hafiz.. "Perancangan Display LED Dot Matrix Menggunakan.Mikrokontroler.ATmega32". Universitas Andalas, Padang., 2013 